\title{
Balanced score-card to create a strategy focused organization at DUBAL, UAE
}

\author{
Bharathan Viswanathan ${ }^{1 *}$, Philip Thomas ${ }^{2}$, Ananthraman Pichai ${ }^{3}$, Naseer Khan ${ }^{4}$ \\ ${ }^{1}$ Skyline University College, University City of Sharjah, UAE \\ ${ }^{2}$ College of Business Administration, AL Dar University College, Dubai, UAE \\ ${ }^{3}$ Manipal University, Dubai, UAE \\ ${ }^{4}$ College of Business Studies, Al-Ghurair University, Dubai, UAE \\ *Corresponding author E-mail: vbharathan@gmail.com
}

Copyright $\odot 2014$ Dr. Bharathan Viswanathan et al. This is an open access article distributed under the Creative Commons Attribution License, which permits unrestricted use, distribution, and reproduction in any medium, provided the original work is properly cited.

\begin{abstract}
The Balanced Scorecard (BSC) concept was introduced at DUBAL in the year 2005 and continued to be used as a key tool for strategy management, execution and reporting. The core areas that were covered in DUBAL's Balanced Scorecard measures include Financial Performance, Customer Focus, Internal Process, Learning and Growth - which collectively embrace the company's business (economic and social performance) and sustainability (environmental and social governance performance) priorities. Though the BSC frame work in DUBAL's Power operations department was implemented successfully, it was not of much use in certain areas like energy-saving, power conservation etc. Moreover there was no total involvement of operational staff and there was little or no communication across the board. The present study attempts to identify the existence of any differences in the users' perceived notion on Balanced Scorecard, identify the factors causing this lag-behind and suggest measures for improvisation, which would correct the imbalances in the implementation and enhance the business performance.
\end{abstract}

Keywords: Balanced Score Card, DUBAL, Financial-Performance, Customer-Focus, Internal-Process and Learning and Growth.

\section{Introduction}

The Balanced Scorecard (BSC) is not only a collection of measures but is also a sort of strategic management system to clarify and implement strategy. There are four perspectives in a balanced scorecard: Learning and Growth Perspective, Internal Business Perspective, Customer Perspective and Financial Perspective. For each of those perspectives multiple measures are linked together in a series of cause-effect relationships. Cause and effect, also called leading and lagging indicators, are measures where a change in the first measure, the leading measure, results in a change in the second measure, the lagging measure [1] .The BSC concept was introduced at DUBAL in the year 2005 and is being used as a key tool for strategy management, execution and reporting. With the BSC framework, DUBAL had developed not only into a strategy-focused organization, but was able to convert its vision of becoming one of the top five producers of aluminum across the globe [2].

DUBAL had introduced the BSC system to be used throughout all its departments to improve the vision in planning and strategic implementation. However there was a need to review, plan and deploy the existing BSC practices in the Dubal-Power operations Department, due to the shortfall in the expected outcome of the Departmental objectives. This study attempts to understand the various initiatives taken by the Department in using the BSC to "align the organization to the strategy and translate the strategy into operational terms", as quoted by Van Der Woerd, F. and Van Den Brink, T., [3]. 


\section{Materials and methods}

\subsection{Need for the study}

Though the BSC frame work in Dubal-Power operations Department was implemented successfully, there were certain areas like energy saving, power conservation etc., involvement of operational staff, communication across the board etc., still lagging behind and BSC framework was not doing much about it. The present study attempts to identify existence of any differences in the users' perceived notion on BSC, identify the factors causing this lag-behind, or any other technical aspects that needs to be reviewed. There was also the need to know the perceptions and the opinions of the users of BSC, the extent to which the BSC implementation had affected the business performance, in terms of the key indicators whether the results were improved and to learn how the process of decision making within the department had been influenced by the present BSC framework.

\subsection{Objectives of the study}

The key objectives pursued in the study include, assessing the present BSC collaborative initiatives and measures implemented at DUBAL in general, evaluating the perception of users of BSC measurement system implemented in the Power operations Department in particular, reviewing and suggesting improvements in the practices of BSC framework within the Power operations department.

\subsection{Review of literature}

In their study Robert S. Kaplan and David P.Norton, [4] had analyzed how the Balanced Scorecard complemented financial measures of past performances with measures of the drivers of future performance. The objectives and measures of the scorecard were derived from the Organization's vision and strategy and view Organizational performance from four perspectives: Financial, Customer, Internal business process, Learning and growth. These four perspectives provided the framework for Balanced Scorecard (Ref.Fig1).

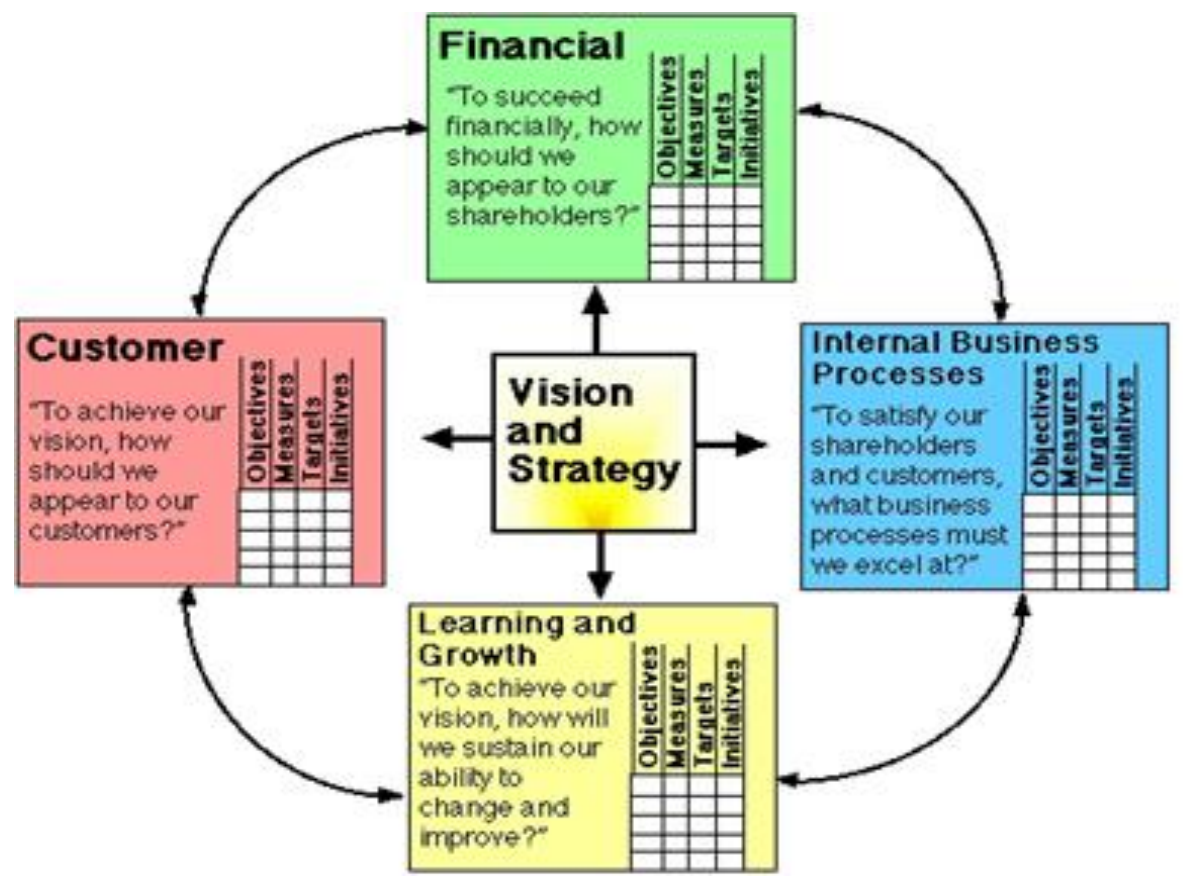

Fig. 1: The Balanced Scorecard Provides a Framework to Translate a Strategy into Operational Terms

The necessity for developing and implementing multidimensional performance measurement systems and strategic management systems had been emphasized in management science [5]. The Balanced Scorecard was relevant both in real world business organizations as well as in tertiary and management education [6]. The Balanced Scorecard was originally proposed by Kaplan, R.S. and Norton, D.P., [7], as a Performance Measurement System (PMS) and subsequently evolved into a comprehensive Strategic Management System (SMS) for the top management. Subsequently it had generated considerable interest and adherence among all the employees. This was demonstrated by the fact that several private sector companies and public bodies have adopted the BSC. [1]. Malmi, T. [8] had confirmed that several articles focusing on the diffusion of the BSC strategy applicable in specific geographic areas had been 
written and many software houses created the tools for BSCs. Also web-based reports and case studies were made available [9]. The relevance, positive role and usefulness of the BSC as SMS tool was appreciated in several earlier studies who made reference of the same [10]. Balanced Scorecard had improved the performance of the employees; it was considered motivating and rewarding for the people to make the strategies more innovative [11]. Each old system was to be replaced with a new system, the same was the case with performance measurement where Balanced Scorecard was very popular and it was the best performance measurement system and its success was dependent upon its proper implementation [12]. Lincoln had quoted the success that they had at Nemours was proof of the usefulness of the Balanced Scorecard[13], the Balanced Scorecard created a balance between short term and long term measures, internal and external business processes, leading and lagging indicators, objective and subjective measures etc.[14]. The perspectives included in the Balanced Scorecard were operational, staff, citizen and resources [15]. Stawar, T., \& Zipple, A., [16] studied and concluded that Balanced Scorecard was much more than the traditional performance measures. Balanced Scorecards was equally applicable, alike private sector, to public sector organizations only after having certain modifications, which may be in the form of additional perspectives [17]. Balanced Scorecard was necessarily good because it covered all the features of the management control system [18]. Balanced Scorecard helped marketers and executives, as it provided measures for both inputs and outcomes, also some organizations might be practicing Balanced Scorecard in some other names and few other companies may be using it without even knowing it [19].

\subsection{Research methodology}

Research methodology is a way to solve the research problems in a systematic manner. As the main idea of the study was to know to what extent the BSC implementation had affected the Power Operation business performance, how the department performance measurement, key indicators and results had been improved using BSC, importance was given to the review of existing BSC framework of the company, using the existing literature, reports etc., and more of secondary data was used in the research. Also a questionnaire was developed to measure users' perception on the "suggested characteristics of Kaplan and Norton's Balanced Scorecard" and was used to conduct interviews/discussions with most of the Managers, Senior Managers and other operational staff in the Power Operation Divisions in DUBAL. The secondary sourced data was collected from DUBAL intranet, department's vision, Power Operation reports, Power Operations strategy, Power Operation monthly statistics- reports, departmental monthly and annual reports, and Personal support from DUBAL "BSC" management office.

\subsubsection{Sampling framework}

Primary data needed was collected through questionnaires issued to senior, middle managers and operational staff who constitute the sample for the study. The Senior Managers were part of the top management team, the middle level managers were linking the top management with the operational executives who were managing the operational activities. Randomly 60 employees were selected from the work force and the questionnaire was distributed to them. Out of the completed questionnaires four were incomplete and rejected, and hence the sample size was only 56. The sample represented around 5\% of the total work force in the organization, who were the users of BSC in DUBAL. We defined the work force consisting of senior managers (30), middle managers (118) and engineers (400) and supervisors (490), totalling to 1038 representing total users of BSC framework in DUBAL, Jebal-Ali, UAE plant.

\section{Results}

\subsection{Data analysis and interpretations}

\subsubsection{BSC Users' perception analysis}

At DUBAL Power and Desalination Department, the Balanced Scorecard was a blend of financial and non-financial measures; it was considered to be a comprehensive performance measurement system. BSC measures the performance of the Department from four different perspectives. These perspectives were financial perspective (quantifiable measures), Customer Perspective (qualitative measures), Internal Business Process Perspective (both quantifiable and qualitative measures) and Learning and growth Perspective (Innovation). On the extent to which the BSC implementation had affected the business performance and in terms of the key indicators whether the results were improved and to learn the extent of decision making process had been affected by the present BSC framework within the department etc., there was a need to know the perceived opinion of the users of BSC, using survey questionnaire analysis. 
Table 1: Middle Managers Perception High on Following Aspects Post BSC Implementation in DUBAL

\begin{tabular}{|c|c|c|c|}
\hline $\begin{array}{l}\text { Sl. } \\
\text { No. }\end{array}$ & Factors & Respondents' perception & Level of Significance @ 0.05 \\
\hline 1 & Factors ensuring above industry earnings for DUBAL & \multirow{7}{*}{$\begin{array}{l}\text { High among Middle Managers } \\
\text { as compared to Senior } \\
\text { Managers and operational level } \\
\text { executives. }\end{array}$} & P-value (0.644)- non-significant \\
\hline 2 & Factors ensuring improved operating margin for Dubai & & P-value (0.468)- non-significant \\
\hline 3 & $\begin{array}{l}\text { Factors influencing Customer service objective of } \\
\text { "Deliver high quality product \& service" }\end{array}$ & & P-value (0.784) - non-significant \\
\hline 4 & $\begin{array}{l}\text { Factors influencing Customer Service Objective of } \\
\text { 'attract and retain' preferred customers }\end{array}$ & & P-value (0.644) - non-significant \\
\hline 5 & $\begin{array}{l}\text { DUBAL's efforts to improve employee alignment for } \\
\text { better BSC implementation is successful }\end{array}$ & & P-value (0.820) - non-significant \\
\hline 6 & $\begin{array}{l}\text { Nurturing the culture of result orientation and customer } \\
\text { focus has improved in DUBAL after the BSC }\end{array}$ & & P-value (0.769) - non-significant \\
\hline 7 & $\begin{array}{l}\text { DUBAL's BSC scheme has resulted in a fair and } \\
\text { consistent application of policy }\end{array}$ & & P-value (0.751) - non-significant \\
\hline
\end{tabular}

Table 2: Senior Managers Perception High on Following Aspects Post BSC Implementation in DUBAL

\begin{tabular}{|c|c|c|c|}
\hline $\begin{array}{l}\text { Sl. } \\
\text { No. }\end{array}$ & Factors & Respondents' perception & Level of Significance @ 0.05 \\
\hline 1 & $\begin{array}{l}\text { Internal process dimensions of DUBAL's BSC } \\
\text { Implementation i: e DUBAL's performance-extending } \\
\text { corporate core values with all business associates while } \\
\text { adhering to local values. }\end{array}$ & \multirow{14}{*}{$\begin{array}{l}\text { High levels of perception } \\
\text { among Senior Managers as } \\
\text { compared to Middle Managers } \\
\text { and operational level } \\
\text { executives. }\end{array}$} & P-value (0.841) - non-significant \\
\hline 2 & $\begin{array}{l}\text { DUBAL 's performance-achieving world class EHS } \\
\text { performance and support EHS initiatives in Industry \& } \\
\text { community }\end{array}$ & & P-value (0.767) - non-significant \\
\hline 3 & $\begin{array}{l}\text { DUBAL 's performance- Optimizing customer base and } \\
\text { market share for selected customers }\end{array}$ & & P-value (0.798) - non-significant \\
\hline 4 & $\begin{array}{l}\text { DUBAL's performance- Enhance and grow customer } \\
\text { awareness of DUBAL Brand }\end{array}$ & & P-value (0.888) - non-significant \\
\hline 5 & $\begin{array}{l}\text { DUBAL 's performance in Improving supply chain } \\
\text { logistics, both Inbound and outbound }\end{array}$ & & P-value (0.805) - non-significant \\
\hline 6 & $\begin{array}{l}\text { DUBAL 's performance-Secure strategic Raw material } \\
\text { and energy supply }\end{array}$ & & P-value (0.725) - non-significant \\
\hline 7 & $\begin{array}{l}\text { DUBAL 's performance- in managing CAPEX to support } \\
\text { Strategic objectives }\end{array}$ & & P-value (0.737) - non-significant \\
\hline 8 & $\begin{array}{l}\text { DUBAL's Performance in focusing on IT developments } \\
\text { to support business needs }\end{array}$ & & P-value (0.785) - non-significant \\
\hline 9 & $\begin{array}{l}\text { DUBAL 's performance to achieve and sustain 'best-in } \\
\text { class' operational effectiveness }\end{array}$ & & P-value (0.748) - non-significant \\
\hline 10 & $\begin{array}{l}\text { DUBAL's self-sufficiency in technology for future } \\
\text { expansion }\end{array}$ & & P-value (0.697) - non-significant \\
\hline 11 & $\begin{array}{l}\text { Post BSC implementation DUBAL is able to attract, } \\
\text { develop and retain skills better }\end{array}$ & & P-value (0.777) - non-significant \\
\hline 12 & $\begin{array}{l}\text { DUBAL's 2-way communication has improved post BSC } \\
\text { implementation }\end{array}$ & & P-value (0.842) - non-significant \\
\hline 13 & DUBAL's Employee empowerment is satisfactory & & P-value (0.718) - non-significant \\
\hline 14 & $\begin{array}{l}\text { UAE Nationals employees are satisfied to be part of } \\
\text { DUBAL }\end{array}$ & & P-value (0.741) - non-significant \\
\hline
\end{tabular}

Table 3: Senior Managers and Middle Managers Perception High on Following Aspects Post BSC Implementation in DUBAL

\begin{tabular}{|l|l|l|l|}
\hline $\begin{array}{l}\text { Sl. } \\
\text { No. }\end{array}$ & Factors & Respondents' perception & Level of Significance @ 0.05 \\
\hline 1 & $\begin{array}{l}\text { Post BSC implementation DUBAL is able to strengthen } \\
\text { leadership skills. }\end{array}$ & $\begin{array}{l}\text { High levels of perception } \\
\text { among Senior Managers and } \\
\text { Middle Managers as compared } \\
\text { to operational level executives. }\end{array}$ & P-value (0.676) - non-significant \\
\hline
\end{tabular}

\subsection{Findings}

\subsubsection{Findings based on users' perception analysis}

1) Respondents' perception on Dubal's Business strategy was very high among Middle Managers (Table-1) as compared to Senior Managers and operational level executives, and the F-test reveals that there was no significant difference in the perception among all classes of respondents.

- This indicates that all the users perceived the uniqueness of the business strategy, understood it well and were able to clearly differentiate it between corporate and business strategy. 
2) Respondents' perception on Dubal Business Strategy driver-outcome relationship showed high levels of perception among operational level executives as compared to Senior Managers and Middle Managers. The F-test reveals that that there was no significant difference in the perception among all classes of respondents

- This indicates that the users understood well the driver-outcome relationship, as part of performance measurement system and also the linkage of budgeting system to the performance systems was well appreciated.

3) Perception on the BSC implementation in DUBAL is able to strengthen leadership skills, is high among all managers (Table-3) as compared to operational staff, as most of the Managers KPA target is well aligned with BSC objectives.

4) Perception on most of the internal process dimensions of DUBAL's BSC Implementation indicated that senior manager's exhibit high mean value (Table-2) and the reason could be that most of the internal process activities of BSC implementation involve the active participation of senior managers as compared to other levels of managers.

- This indicates that the analyses of the perception of respondents on most of the internal process dimensions showed no significant difference in the perception related to

i) Extending corporate core values with all business associates while adhering to local values,

ii) Achieving world class EHS performance and support EHS initiatives in Industry and community,

iii) Optimizing customer base and market share for selected customers, Enhance and grow customer awareness of DUBAL Brand,

iv) Improving supply chain logistics- both inbound and outbound,

v) Focusing on IT developments to support business needs, achieving and sustain 'best-in class' operational effectiveness and self-sufficiency in technology for future expansion.

5) Respondents' perception on most of the Learning and growth dimensions of DUBAL's BSC Implementation indicated high mean value for middle managers (Table-1) and the reason could be on account of almost $50 \%$ of the respondents being middle management level. Further the analyses of the perception of respondents on most of the Learning and growth dimensions showed no significant difference in the perception related to the following:-

a) DUBAL's efforts to improve employee alignment for better BSC implementation was successful.

b) Nurturing the culture of result orientation and customer focus had improved in DUBAL after the BSC.

c) DUBAL's BSC scheme had resulted in a fair and consistent application of policy.

d) Post BSC implementation DUBAL was able to attract, develop and retain skills better.

e) DUBAL's 2-way communication had improved post BSC implementation.

f) UAE Nationals employees were satisfied to be part of DUBAL.

g) Post BSC implementation DUBAL was able to strengthen leadership skills.

h) DUBAL's Employee empowerment was satisfactory.

\subsubsection{Findings based on review of existing performance measurement system}

Though the respondents' perception seemed to be extremely positive in the survey, there were certain parameters in the present BSC framework, where in the performance measures need to be improved.

1) Few of the Customer Perspectives recorded just 'on target' performance, which needs to be addressed for improving their performance to 'above target'

a) Deliver high quality products and services.

b) Promote DUBAL brand

2) Following Internal Business Progress Perspectives recorded just 'on target' performance, which needs to be addressed for improving their performance to 'above target'

a) Aggressively optimize procurement of raw materials.

b) Develop and market reduction technology.

c) Effective implementation of CAPEX projects.

d) Achieve and sustain best-in-class operational.

e) Build new markets and expand customer base and market share.

f) Manage strategic partnership with core business and upstream.

g) Be a good and pro-active corporate citizen.

h) Achieve world-class Environment Health Services (EHS) performance

3) Few of the Learning and Growth Perspectives recorded just 'On target' performance, which needs to be addressed for improving their performance to 'above target'

a) Nurture the culture of result-orientation and customer-focus

b) Attract, retain and develop skills.

\section{Discussion}

There are two components to any performance measurement system: one is the metrics used for evaluation and another is the objects that are evaluated. In the present case, the users of the BSC in Dubal had expressed extreme satisfaction 
over most of the perspectives of the BSC framework. The overwhelmingly positive feedback received from the users of BSC indicates that there were no issues related to the objects of the system. But the fact that certain areas like delivering high quality products and services, promoting DUBAL brand, energy saving, total involvement of operational staff, communication across the board etc., are still lagging behind, showed that all was not well with regards to the BSC implementation at DUBAL. This meant that the other component ie., the metrics used needs to be reviewed and also the performance review mechanism needs to be re-visited.

Analysis of Balanced Score Card as to where it fits in DUBAL's strategy showed that the upper layer programs of Organization consisting of the Purpose, Strategic themes, Competencies and Mission and Vision were managed by the top management; the bottom layer manages activities such as the Measures, Objectives, Targets and Initiatives of the Organization etc., were within the ambit of Middle Managers.. There exists a GAP between these two layers, which was supposedly to be filled-in by the Balanced score card.

The barriers to the successful implementation of the Balanced Scorecard was inclusive of

a) The Vision barrier- only $5 \%$ of the workforce understand the strategy,

b) The people barrier- only $25 \%$ of managers have incentives linked to overall strategies,

c) The management barriers- $85 \%$ of executive teams spend less than one hour a month discussing strategy and the

d) Resource barrier- $60 \%$ of people in DUBAL do not link budgets to strategy.

Based on the analysis of DUBAL (Power \& Desalination) BSC model implementation and summarised perception analysis of the senior, middle managers and operational executives following areas needed greater attention for better performance related to the four perspectives:-

1) Financial - Maximize revenue from water sales, Improve and sustain cost competitiveness of DUBAL, Never running-out of cash to finance expansion, mitigate financial risk and ensure investment returns.

2) Customer - Prompt resolution of complaints and technical queries, provide flexibility on commercial terms, Enhance and retain customer satisfaction, Ensure on-time deliveries, every-time, Deliver high quality products in a consistent and sustainable manner and provide customized solutions

3) Internal processes - Extend corporate core values with all business associates and adhere to local values, Proactively support community, Achieve World Class EHS- performance and support industry/community, Optimise customer base and market share for selected customers, Enhance and grow customer awareness of DUBAL Brand, Create flexible product mix capabilities, Resource optimisation and Operational excellence.

4) Learning and Growth - Improve employee alignment and nurture the culture and result orientation and customer focus, Fairness and consistent application of employee policy, Attract, develop and retain skill in line with industry norms, Strengthen leadership skills, 2-way communication systems, employee empowerment and Increase the number of UAE national appointment in P\&D.

The main results of the paper are summarized as under:-

Focus on original results and discuss those compared with results from references or compare simulations with experimental results. Do not compare simulations with other simulations if you don't have a very good reason to do so. Do not expect the reader to search for your results over the article and references. Do not present as results a wellknown theory. A good result may contain only a good explanation of the researchers' novel idea, a measuring methodology, a design or all of them. Be specific naming the results: the results are pure theoretical, simulations, simulations followed by experimental measurements, experimental measurements or manufactured prototypes, etc.

\section{Conclusion}

At DUBAL, for the Managers the Balanced Scorecard is bound to help in creating alignment between Corporate and Departmental Goals, which in turn will enhance the communication system -inter and intra Departments and would open the road for synergy opportunities and processes improvement that would lead to performance enhancement for the whole Organization. From survey results, we could see that BSC worked well for DUBAL in monitoring key parameters and achieving goals. Using the Balanced Scorecard as a Guide-post for performance at DUBAL P \& D was a story of successful implementation, but there were various areas that call for improvisation to make it a story of success. Staff must continue to identify opportunities to reduce cost, increase productivity and improve efficiency. Currently initiatives were put as suggestions but yet to be converted to practices. The chosen initiative must support the department objectives and improvement in communication of specific initiatives to the respective supervisors must be achieved. Once initiatives were accepted by the supervisor, the staff must add it to their performance agreement and in the Initiatives Screening Grid (ISD). Frequency and quality of reporting on the progress must be improved. Initiatives and processes that are currently done, but not in-line with or which did not contribute to the departmental objectives are to be identified, pruned and deleted. Rewarding system for success must be in place at all levels. Another parameter to be added into DUBAL BSC system is information on Energy savings projects that must be implemented for the company as a whole, and not department-wise. One of the recent new challenges taking place at the Power and Desalination plant was to implement and certify towards Energy Management 50001:2011 international standard. It was suggested to add as many parameters into DUBAL BSC system to monitor and control the system requirements. 


\section{Scope for future research}

In future more people can be included in the surveys in order to acquire further information. Also it would be very useful to compare the findings of this report with the findings of a company or companies that already adopted and implemented the Balanced Scorecard. Moreover, further research and analysis for each specific Business Unit in DUBAL would give better insights of the Balanced Scorecard implementation and its usage as a communication system, as each Business Unit offered different types of products and services along with different processes and action plans to achieve their set targets.

\section{Acknowledgements}

The Authors jointly express their acknowledgement for the support given by the managers and staff of the Department of Power and Desalination, DUBAL for actively participating in the survey and supporting the cause of the research analysis. In this regard the support and encouragement given by MR.ABDUL HAMEED General Manager-Power Operation and other Senior Management team in particular, for furnishing the relevant information and details of the Balanced Scorecard system, operational data etc., is highly appreciable.

\section{References}

[1] Kaplan, R.S., and D.P. Norton. 2001, "The Strategy-Focused Organization", Boston, MA: Harvard Business School Press.

[2] Braam, G.J.M. and Nijssen, E.J. (2004) "Performance effects of using the Balanced Scorecard: a note on the Dutch experience", Long range planning, Vol. 37, No. 4, pp. 335-349. http://dx.doi.org/10.1016/j.lrp.2004.04.007.

[3] Van Der Woerd, F. and Van Den Brink, T. (2004) "Feasibility of a Responsive Business Scorecard-a pilot study", Journal of Business Ethics, Vol. 55, No. 2, pp. 173-186. http://dx.doi.org/10.1007/s10551-004-1900-3.

[4] Robert S.Kaplan; David P.Norton, "The Balanced Scorecard: Translating strategy into action" Harvard Business Review Press Boston, Massachusetts, 1996, pp.8-9.

[5] Morgan, M. (1998), "Improving business performace: are you measuring up?" Manage, Vol. 49, No. 2, p.10.

[6] Akkermans, H.A. and van Oorschot, K.E. (2005), "Relevance assumed: a case study of balanced scorecard development using system dynamics", Journal of the Operational Research Society, Vol. 56 No. 8, pp. 931-941. http://dx.doi.org/10.1057/palgrave.jors.2601923.

[7] Kaplan, R.S. and Norton, D.P. (1992), "The Balanced Scorecard: measures that drive performance", Harvard Business Review, Vol. 70 No. 1, pp. 71-9.

[8] Malmi, T. (2001), "Balanced Scorecards in Finnish companies: a research note", Management Accounting Research, Vol. 12 No. 2 , pp. $207-$ 20. http://dx.doi.org/10.1006/mare.2000.0154.

[9] Marr, B. and Neely, A. (2003), "Automating the Balanced Scorecard - selection criteria to identify appropriate software applications", Measuring Business Excellence, Vol. 7 No. 3, pp. 29-36. http://dx.doi.org/10.1108/13683040310496480.

[10] Davis, S. and Albright, T.L. (2004), "An investigation of the effect of Balanced Scorecard implementation on financial performance", Management Accounting Research, Vol. 15 No. 2, pp. 145-53. http://dx.doi.org/10.1016/j.mar.2003.11.001.

[11] Barkley, S. (2000). Are You in Balance? Outlook, 67(A), 34.

[12] Kaydos, W. (2004). What Should Your Company Measure Beside Financial Results? Balanced Scorecard Institute.

[13] Lincoln, M. (2008). News Research Shows Balanced Scorecard Helps Companies Achieve an Execution Premium. Business Wire.

[14] Martin, J. R. (2004). The Balanced Scorecard Concepts. White Paper- Balanced Scorecard Institute.

[15] Elefalk Kjell (2001). The balanced Scorecard of Swedish Police Service; 7000 officers in total quality management project. Total Quality Management, pp 958-966.

[16] Stawar, T., \& Zipple, A. (2002). The strategy-focused organization: how balanced scorecard companies thrive in the new business environment, Psychiatric Rehabilitation Journal, vol.26 (2), pp 212 http://dx.doi.org/10.1037/h0094560

[17] Rhom, H. (2004). A Balancing Act. PERFORM, 2(2), pp1-8.

[18] Stella, Mooraj, (1999). The Balanced Scorecard: a necessary good or an unnecessary evil. Europeon Management Journal, vol.1no. 7(5), pp 481-491.

[19] Lincoln, M. (2008). News Research Shows Balanced Scorecard Helps Companies Achieve an Execution Premium. Business Wire. 